\title{
Specific interactions of the english language teacher and the logopedist when working with bilingual children
}

\author{
A.P. Demidova ${ }^{1 *}$, V.N. Zinovieva ${ }^{2}$, and L.S. Petrunina ${ }^{3}$ \\ ${ }^{1}$ The Tsiolkovsky Kaluga State University, Kaluga, Russia \\ ${ }^{2}$ The Tsiolkovsky Kaluga State University, Kaluga, Russia \\ ${ }^{3}$ The Tsiolkovsky Kaluga State University, Kaluga, Russia; MKOU Pyatovsky secondary school, \\ Pyatovsky, Russia
}

\begin{abstract}
The article examines the specifics of the interaction between an English teacher and a speech therapist within the educational process; substantiated the specifics of constructing binary lessons; the peculiarity of the formation of knowledge assimilation by bilingual children in foreign language lessons is revealed.
\end{abstract}

\section{A problem statement}

Due to the rapidly developing requirements for modern society, the younger generation is extremely necessary to learn English for more successful self-expression in the future. For this, the study of a foreign language was introduced to school from the second grade. But there are exceptions to each rule, observing children of different ages, I can say that children come to school with various speech abnormalities, which leads to a low quality of knowledge, as well as disorders in the emotional and personal sphere. In his works, B. Kielhöfer, notes that those with speech disorders are aggravated by new, specific language material when studying a foreign language [1].

Having a wide variety of methodological literature on teaching English to schoolchildren, teaching children with speech disorders involves the search and use of new effective methods of work that contribute to the assimilation of a foreign language by children with speech disorders.

To date, the features of the manifestation of speech disorders in children in the process of learning their native and English languages have been sufficiently studied. This problem was dealt with by such scientists as: T.B. Filicheva, M.S. Povzner, T.A. Vlasova, I.A. Zimnyaya, E.N. Solovova, L.V. Shcherba and others. With all the variety of forms of speech impairment, the most common, in most cases, is a violation of the soundpronunciation side of speech, which occurs both as an independent violation and in the complex of a more complex speech disorder. Speech disorders make it difficult for children to master the phonetic structure of the language system.

\footnotetext{
* Corresponding author: ipcs-profped@yandex.ru
} 
Most scientists agree that bilingualism is a positive factor for the formation of logic, thinking, speed of reaction.

Today bilingualism is an urgent problem. Bilingualism is the ability of a different circle of people to communicate in two languages, and in most cases it is good in both languages. People who are fluent in two languages are called bilinguals, more than two are polylinguals, and more than six are polyglots [2].

Ryabtseva O.M. defines bilingualism as the ability to use two language systems for communication.

It is no secret that many schoolchildren experience difficulties studying Russian, for example, they cannot master writing, reading, counting, they also have problems with assimilation and understanding of texts orally, as well as with logical thinking, at the same time it is difficult imagine what could be then when learning English.

Since the language is the direct and main function of a particular nationality, bilinguals who are carriers of two language groups, at the same time are carriers of the characteristics of these groups, in short, bilinguals belong to different groups of people [3].

Filimonova M.S., Krylov D.A. were engaged in bilingualism as a trend in the linguistic development of modern society, who believe that today bilingualism requires close attention from the educational process.

Learning a second foreign language, and in this case, English, is a legitimate desire of modern parents who are not inferior to the realities of modern society. Most parents fear that the introduction of English in general education school from the second grade may negatively affect the quality of mastering the first (native) language.

Not only Russian researchers, but also researchers from foreign countries note that interest in learning a foreign language has been growing at an incredible rate recently, however, at the same time, there is an increase in the number of children who simply need the help of speech therapists. Such children require a special approach at school, and especially when learning a second foreign language [4].

Unfortunately, the school educational program does not take into account the peculiarities of students' speech disorders, even if they have slight deviations in speech, they all attend the lesson on general terms. And, if we take such a diagnosis as "phonemic hearing impairment", then such children receive very little attention [5].

New educational standards and trends dictate new conditions in the field of education. According to statistics, the number of students who have learning difficulties is growing from year to year. Analyzing the data obtained during the survey of children, which was carried out on the basis of a general education school, $20 \%$ of first-graders have speech therapy disorders, as for first-graders of our school, here the figure is slightly higher $-25 \%$. Approximately $25-30 \%$ of primary school students experience learning problems, some even have mental and speech retardation. By the end of the academic year, using all the methods, selecting correctional work, this figure is significantly reduced, and already varies from $13-17 \%$ throughout the initial level.

T.A. Znamenskaya determined that language transfer is possible if the language systems of the two languages are comparable. This means that everything in languages should be the same, but English and Russian differ in the grammatical aspect of speech. Also, the presence of an accent is a hallmark of the incorrect imposition of one language on another.

Complex constructions and clichés - such students will not be assimilated, since they have a very low level of development of their native language. It is possible to carry out such work only for the purpose of acquaintance.

A foreign language teacher can make his own program for teaching such classes or make changes to the general education curriculum. This program is approved at the school organizations or at the school teachers' council.

The teacher has the right: 
- reduce the volume of the studied vocabulary;

- choose easy-to-remember constructions for presentation;

- pick up simplified texts;

- reduce the requirements for learning a foreign language.

Learning a second foreign language for a child is a difficult task, in which case desire is important. Desire itself is a powerful impetus for further action. Family, in this case, will be an important factor in maintaining this kind of desire. At the initial stages, the child's support, faith in him and his strength is simply necessary. But, at the same time, a foreign language may well have a positive impact on the development of phonemic perception in students, by properly organizing the educational process [6].

\subsection{The objective of the work}

Studying in the same class as children who do not have speech impairments, children can face serious problems.

They may lose confidence in themselves, the desire to study a foreign language both in the classroom and at home disappears, fears and complexes appear in front of the class. At the initial stage, cooperation between all participants in the general educational process is simply necessary, which can lead to positive results. Everyone should work so that the child has self-confidence, an interest in the subject.

Correctional pedagogical work is closely related to teaching a foreign language to students with speech disorders.

The development of correctional work is carried out as follows:

- formation of the main articulatory apparatus;

- development of memory, thinking, attention;

- formation of traits of a harmonious personality;

- development of gaming activities.

Since play activity is the leading type of activity among younger schoolchildren, it is better to build learning a foreign language in such a form, with a variable change of activities that will help prevent distraction and reduce fatigue [7].

The use of a playful form in foreign language lessons for students with speech disorders contributes to the easy assimilation of the material provided by the teacher, in this case it is good to use pictures, cubes, some kind of play sets. The development of a game concept promotes activation of attention, memory and general mental development [8].

As you know, there is no such physically and mentally normal person who is not able to master their native language to the full, therefore, the study of a foreign language is accessible. In any country there are people with speech impairments, as for a foreign language, it is natural that children may not be able to pronounce some language units, but this may not be a speech defect [9].

The main goal of a teacher at school is to organize and direct the personal initiative of students to acquire knowledge, to make lessons loved, learning - accessible and attractive, not to neglect the repetition and analysis of previously studied material. This enables all students to assimilate and memorize educational material in accordance with their individual capabilities. It is necessary to give each student a chance to receive an assessment for his work, according to his personal attitudes and capabilities.

In the process of developing educational material and methodological tools, it is necessary to take into account the age, individual and psychological characteristics of children in this category, as well as the structure of their speech defect. All training should be carried out by the method of subject-based practical activities of students with speech support and should be aimed at developing meaningful, correct ideas on the material 
covered and practical skills. The main method of teaching should be the organization of constant active subject-based practical activity in the classroom.

Some speech defects of the native language can positively say on the pronunciation of some linguistic units of the English language. So, for example, the burr of Russianspeaking students has a practically positive effect on the pronunciation of the English and German sound $[\mathrm{r}]$. And, also, after correcting the Russian defect, you can practically bring to automatism, for example, replacing " $\mathrm{r}$ " with "l". In this regard, we can add that corrective speech therapy work on the elimination of speech defects can be carried out in parallel with the study of a foreign language [10].

However, setting the pronunciation of sounds of a foreign language is a kind of speech therapy work, aimed at close attention to the activity of the articulatory apparatus [11].

Akulina E.V. believes that at school it is necessary to devote more time to the difference in pronunciation of sounds in English, i.e. to its interference. Depending on the pronunciation of the sound, the word can change its meaning completely, so for example, if in the word sheep (sheep) pronounce briefly "and", you get a completely different meaning - "ship" (ship).

Observing students at school, as a teacher of a foreign language and as a speech therapist, I can say that if students have speech problems in Russian, then they manifest themselves in a foreign language. The reason for the appearance of speech disorders in a foreign language is not the very introduction and study of a foreign language. The formation of knowledge of a second foreign language in a child grows on the basis of the first, and the level of speech development of the first language sets the basis for learning the second

In their works, Khlobystina I.Yu., Demidova A.P. note that elementary school students with speech disorders write words as they say. They are characterized by: replacements of vowels and agree, missing letters, incorrect distinction between hard / soft and voiceless / voiced [12].

In order to teach children, correct and good pronunciation in English, you need to use such trained exercises in the lesson that will contribute to the development of phonemic perception of the English language, as well as the setting of correct articulation. One of such exercises can be a "phonemic warm-up", which helps prepare the speech apparatus for pronouncing sounds in a foreign language.

The order of mastering a second foreign language begins, first of all, with the mastery of the names of objects and concepts. The more a foreign language enters into the everyday life of a student, the faster the meanings of words are redistributed, and the thought is built differently.

Knowing two foreign languages, I can say from my own experience that in most cases I think in a language that is not my native language, but in English or German, since these languages occupy a large place in my life. As for our case, this is a student who needs to acquire new knowledge, skills and abilities; receive new assessments, which later can lead to positive or negative dynamics from learning new things.

After 3-4 lessons of a foreign language, some children immediately notice speech disorders. And my task, first of all, as an English teacher, is to instill knowledge in students, to bring them to a level at which they could communicate with foreign native speakers, even if the students have speech disorders.

For children - billing systems are characterized by violations that they have in Russian. These can be children with phonetic-phonemic, phonemic, general underdevelopment of speech, namely: a violation of the perception of phonemes present in both languages, a violation of the pronunciation of phonemes, an underdevelopment of the lexicalgrammatical structure of speech in both languages. 


\section{Materials and the results of the research}

After analyzing the nature and severity of difficulties during teaching a foreign language, the effectiveness of additional classes, the results of the speech therapy examinations of the oral and written speech of students, we can conclude that it is necessary to create a special speech therapy group.

Children who came to the first grade underwent speech diagnostics.

In order for students with speech therapy problems to be able to learn a foreign language successfully, I consider it necessary to take into account the following steps [13]:

Determine the speech disorders that the student has

This requires a special survey to help identify the causes. A conversation with parents is needed to collect anamnesis; determine the condition of the bite, tongue, lips, soft and hard palate. Consider having a passive vocabulary by asking your child to read a story or poem. All of the above, taken together, will help determine the nature of speech impairment, as well as provide ways to solve this problem [14].

Divide students into groups

After conducting surveys and finding out that some children have speech impairments, a group should be created, which will include children of this type. This is necessary in order to carry out speech therapy correction work, as well as not to miss the study of a foreign language.

Make classes binary

When working with children with speech disorders, I think that this is the main point in preparing for classes.

Binary classes are a process of interaction of correction and prevention of speech disorders using Russian and foreign languages. I consider to introduce such classes as extracurricular activities, to which only those children who have speech disorders can be invited.

When conducting binary classes, the primary task is to formulate, automate and differentiate the sounds of the English and Russian alphabets. For the formation of phonetic speech skills, it is advisable to use the approaches [15]:

1. Acoustic approach. With this approach, emphasis is placed on the auditory perception of speech, as well as on its imitation.

2. Articulation approach. This approach is characterized by the allocation of three typological groups of phonemes, namely, those that coincide in both languages; those that partially match, and those that do not match at all.

3. Differentiated approach. This type of approach is characterized by the use of various kinds of analyzers that contribute to the formation of all aspects of the phonetic skill.

Acting as a teacher of a foreign language, I believe that for students with speech impairments, the main task is to foster interest in a foreign language, the development of communication skills. In order to prevent mistakes, it is necessary to work on the concept of gender (in English there is no gender), as well as on the structure of the sentence [16].

You need to enter a foreign language competently, preferably at first in a playful way. This is what is done in the extracurricular activities in the first grade. Since in the first grade, children do not have a foreign language lesson in the educational program, acquaintance with a foreign language is assigned to classes during extracurricular activities. The process is organized in a game form.

Speech material is tweaked taking into account the age, interests of the students. The teaching material becomes more complex with each class. Problems associated with speech disorders are easier to correct at the initial stage of learning a foreign language. Correctly organized teaching of a foreign language, using the speech therapy part, contributes to the development of younger students, raises the educational and cultural level of students [14]. 
Also, a typical mistake in the process of learning English can be: relaxed pronunciation, therefore it is necessary to develop muscle tension of the lips and tongue. For this, articulatory gymnastics comes to the rescue [10].

For example, to prevent mistakes during articulation of English sounds "t" "d", special language exercises are performed:

a) find the most convex part of the alveoli with the tip of the tongue, make repeated movements from the upper teeth to the alveoli, and vice versa;

b) pronounce the English sounds "t", "d" at the beginning of the word: ten (ten), table (table), day (day), dinner (dinner);

c) pronounce the English sounds " $\mathrm{t}$ ", "d" in the middle and at the end of words: actor (actor), at (c), child (child), good (good);

d) to consolidate the skills of articulating the sounds " $t$ ", "d" in the process of reading a coherent text and the use of these sounds in oral speech.

Exercises for the upper and lower lip:

a) slightly raise the upper lip, open the edge of the upper teeth and press the lower lip to them; lower the lower lip, open the lower teeth. Repeat this movement, the upper lip does not move. Slowly and carefully pronounce the English "v" sound several times. Next, we read the words veto (veto), very (very), visit (visit);

b) the lips are vigorously extended forward. Exhale air forcefully through a small hole. Repeat this movement many times, and then pronounce the English sound "w", then the words well (good), wig (wig), west (west).

Without close collective interaction between a speech therapist and parents, successful elimination of speech therapy problems is impossible. School experience shows that parents whose children were found to have speech disorders during learning a foreign language are less motivated to carry out corrective work with children than parents whose children were found to have violations at the initial stage of school life.

For such parents, educational work is simply necessary so that parents of this category become allies of correctional work. For these purposes, an educational organization and a speech therapist can hold joint parenting meetings, attend binary classes [2].

It is necessary to evaluate students not so much by the results achieved, but by the efforts and efforts of the students.

Do not get upset when children do not memorize words the first time, cannot pronounce a sound or word correctly, do not understand grammatical material.

For a group of students with speech disorders, special exercises were developed, which took into account the peculiarities of mastering the English language, according to the calendar-thematic planning. All students of the school study according to the textbook "Rainbow English", where the main characters are the Barker family and their son John.

To develop an interest in the language, John Barker was taken as the main character who accompanies the children, learning English with them. John Barker is a guide to the world of the English language.

Each lesson begins with phonetic exercises, which are useful for all students studying foreign languages. Phonetic exercises should be carried out in a positive way and emotionally, correcting students' mistakes. In this case, the teacher is the standard of speech, students must see the teacher's face. An accompanying presentation showing correct articulation may be more effective. Below are examples of some of the exercises used in the Binary Lessons.

Exercise to differentiate letters and sounds. Most children have phonetic-phonemic speech impairment, meaning that students write down words the way they hear them. Students are offered multiple repetition of phonemes, as well as the correlation of words with the studied phoneme. For example, in the lesson, children study the letter Aa, the teacher explains the rules for reading this letter, and then the children read the suggested 
words and distribute the words into columns corresponding to the sounds. Looking at these words, the child compares the phoneme with the letter.

Exercise to overcome difficulties in the use of the verb "to be". To study the verb "to be, is, to be", a scheme is used, at the head of which is the verb itself, and three arrows drawn down from it indicate its varieties, according to pronouns. Students are presented with blank exercises where they should place the given verb. To relieve difficulties, there is a scheme in front of the students' eyes, according to which they can use, performing these exercises.

Exercises for learning personal pronouns. Children are given a table, illustrated with pictures, where you can see which pronoun and what it means. All pronouns are signed with translation. Exercises are given in which students must replace the corresponding pronouns. This type of exercise is aimed at the formation of competent speech.

Each exercise is accompanied by guidelines and instructions for a foreign language teacher. All exercises are aimed at practicing the correct pronunciation of sounds and letters, as well as their differentiation. When developing the exercises, all the individual and age characteristics of schoolchildren were taken into account.

Exercises are aimed, by and large, at the formation and improvement of reading skills in children who have severe speech disorders. These exercises were developed closely with foreign language teachers who faced these kinds of problems.

\section{Conclusions}

Thus, bilingualism is not a contributing factor for students' speech errors. It can be argued that bilingualism is amenable to adjustment, since the figures at the end of the year differ significantly from those obtained when collecting information.

The following have been performed:

- studied the theoretical aspects of the problem under discussion;

- features of school age with speech disorders have been studied;

- the features of the formation of reading in English are considered;

- a series of exercises has been developed for the formation of knowledge of the English language.

The main criteria for assessing the effectiveness of the interaction between a speech therapist and an English teacher are the results of a speech therapy examination at the beginning and end of the academic year. Academic success, improving the psychological state, increasing interest in a foreign language, as well as the absence of fear of the team.

In conclusion, I would like to emphasize once again that children with speech disorders require special attention to themselves, an understanding of their problems, the patience of a teacher and the help of everyone who works with them. The modern period of development of the preschool education and upbringing system is characterized by great interest in early teaching of foreign languages. particular - English.

All speech disorders come from the native language. Bilingual students with speech problems need qualified help. Problems of this kind can be solved by the collective efforts of various kinds of specialists who can competently build a lesson. After analyzing the nature and severity of difficulties during teaching a foreign language, the effectiveness of additional classes, the results of the speech therapy examinations of the oral and written speech of students, it can be concluded that it is necessary to create a special speech therapy group.

All together, it provides favorable conditions for preventing mistakes during the teaching of children with speech disabilities, and also creates comfortable conditions for the normal mastery of the English language, which contributes to the realization of the child 
and his development in modern society, where knowledge of the English language is a prestigious and necessary condition for obtaining better work.

\section{References}

1. B. Kielhöfer, S. Jonekeit, Bilingual child rearing, 11, 109 (Tübingen: Stauffenburg Verlag Brigitte Narr, GmbH, 2006)

2. N.A. Rumega, Diagnostics and correction of speech disorders in children with bilingualism (2013)

3. O.M. Ryavtseva, Bilingualism in the modern world Izvestia SFedU, p. 116-122 (Technical science, 2011)

4. V. Triarchi-Herrmann, Multilingual Education, How you can support your child, p. 135 (Munich: Ernst Reinhardt Verlag, 2003)

5. T.A. Znamenskaya, Formation of bilingual competence in the study of a foreign language, p. 94 (Education and Science, 2013)

6. N.V. Baryshnikov, Multilingvodidaktika, Foreign languages at school, 5, 29-33 (2004)

7. A. Pavlenko, The Bilingual Mental Lexicon: Interdisciplinary Approaches, Bilingual Education and Bilingualism, p. 272 (Great Britain: Cromwell Press Ltd, 2009)

8. B.M. Esadzhanyan, On the problem of defining "bilingualism" and "bilingual education", World of the Russian word, 4, 51-54 (2003)

9. G.N. Chirsheva, Children's bilingualism: simultaneous acquisition of two languages (SPb.: Zlatoust, 2012)

10. J. Bagana, E.V. Khapilina, Contact linguistics: interaction of languages and bilingualism (2010)

11. E.V. Akulina, Interference in teaching phonetics of the German language, Foreign languages at school, 5, 46-49 (2001)

12. I.Yu. Khlobystova, A.P. Demidova, Interaction of specialists in the correction of dysgraphia within the framework of inclusive education, Problems of modern pedagogical education, p. 206 (Yalta, 2019)

13. R.I. Lalaeva, Speech therapy work in correctional classes (2001)

14. M.V. Balamakova, Variation of worldview phenomena in native speakers and bilinguals, Phonetic variance: bilingualism and diglossia. (Ivanovo, 2000)

15. A.A. Zalevskaya, I.A. Medvedeva, Psycholinguistic problems of educational bilingualism, p. 322 (Tver, 2002)

16. J. Jong de Ester, Effective Bilingual Education: from Theory to Academic Achievement in a Two-Way Bilingual Program , Bilingual Res.J., 26 (1), (Spring, 2002) 